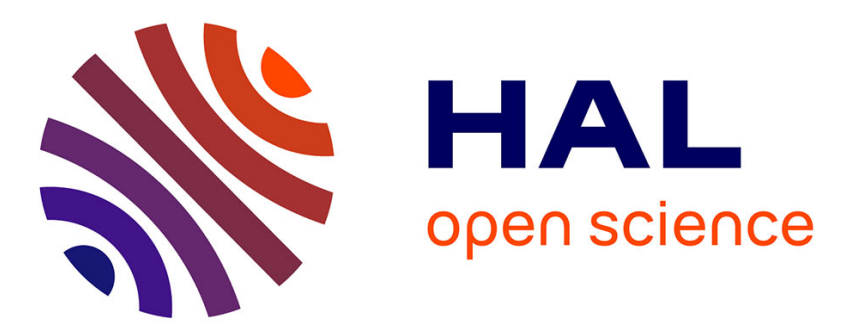

\title{
Electrochemical Synthesis of an Organometallic Material Based on Polypyrrole/MnO2 as High-Performance Cathode
}

Waffa Rakhrour, Djamel Selloum, Abdellah Henni, Noureddine Cherrad, Imene Chikouche, Mokhtar Benalia, Sarra Mouffok, Mabrouk Djedid, Nacira Bouzar, Sophie Tingry

\section{To cite this version:}

Waffa Rakhrour, Djamel Selloum, Abdellah Henni, Noureddine Cherrad, Imene Chikouche, et al.. Electrochemical Synthesis of an Organometallic Material Based on Polypyrrole/MnO2 as HighPerformance Cathode. Journal of Inorganic and Organometallic Polymers and Materials, 2021, 10.1007/s10904-020-01664-w . hal-03009668

\section{HAL Id: hal-03009668 https://hal.science/hal-03009668}

Submitted on 19 Nov 2020

HAL is a multi-disciplinary open access archive for the deposit and dissemination of scientific research documents, whether they are published or not. The documents may come from teaching and research institutions in France or abroad, or from public or private research centers.
L'archive ouverte pluridisciplinaire HAL, est destinée au dépôt et à la diffusion de documents scientifiques de niveau recherche, publiés ou non, émanant des établissements d'enseignement et de recherche français ou étrangers, des laboratoires publics ou privés. 


\section{Electrochemical synthesis of an organometallic material based on polypyrrole/ $\mathrm{MnO}_{2}$ as high-performance cathode}

Waffa Rakhrour ${ }^{1}$, Djamel Selloum ${ }^{1 *}$, Abdellah Henni ${ }^{1}$, Noureddine Cherrad ${ }^{1}$, Imene Chikouche $^{2}$, Mokhtar Benalia ${ }^{3}$, Sarra Mouffok ${ }^{4}$, Mabrouk Djedid $^{3}$, Nacira Bouzar $^{3}$, Sophie Tingry ${ }^{5}$

${ }^{1}$ Lab. Dynamic Interactions and Reactivity of Systems, Kasdi Merbah University, Ouargla, 30000, Algeria

${ }^{2}$ Laboratoire Croissance et Caractérisation de Nouveaux Semi-conducteurs, Université Ferhat Abbas, Sétif-1, Algeria

${ }^{3}$ Laboratory of Process Engineering, Laghouat University, Laghouat, Algeria

${ }^{4}$ Centre de Recherche Scientifique et Technique en Analyses Physico-Chimiques (CRAPC), Ouargla, 30000, Algeria

${ }^{5}$ Institut Européen des Membranes, IEM - UMR 5635, ENSCM, CNRS, Univ Montpellier, Montpellier, France

* Corresponding Author -mail: selloumdjamel@gmail.com, selloum.djamel@univ-ouargla.dz

(Djamel Selloum) 


\begin{abstract}
We report herein the design of promising composite material as a cathode in a rechargeable battery by combining the properties of polypyrrole (PPy) and $\mathrm{MnO}_{2}$ particles. The composites were prepared by electropolymerization of the pyrrole monomer followed by electrodeposition of a manganese salt suspension by two methods. The first method involved the formation of $\mathrm{MnO}_{2}$ in situ in the PPy/ITO electrode, while the second method involved first a preliminary adsorption of $\mathrm{Mn}^{2+}$ ions in the polymer, followed by an electrochemical of the electrode. The morphology of the resulting composite materials $\left(\mathrm{PPy} / \mathrm{MnO}_{2}\right)$ was studied by Energy-dispersive X-ray spectroscopy (EDS), X-ray diffractometry (XRD), scanning electron microscopy (SEM), Fourier-transform infrared (FTIR). The investigations of the electrochemical properties of the composite electrodes show that the presence of $\mathrm{MnO}_{2}$ play an important role in improving the surface of polymer films, which leads to lower charge transfer resistance and higher electrode activity. For the optimal synthesis method, the electrode generates a maximum current of up to $-7.9 \mathrm{~mA} \cdot \mathrm{cm}^{-2}$ for the oxygen reduction reaction, which is eight times the current density delivered by the electrode without PPy.
\end{abstract}

Keywords: composite electrodes; polypyrrol; manganese dioxide; electrodeposition; oxygen reduction 


\section{Introduction}

Energy requirements have led to the intensification of electrochemical generators and batteries [1-4], whose electrochemical performance depends mainly on the nature and structure of the electrode materials (anode and cathode electrodes) [5,6]. The efficiency of these conventional batteries is still limited by a low cyclability [7,8]. Transition metal oxides have been extensively investigated as electrode materials for batteries [9-15]. A great attention has been devoted to manganese dioxide $\left(\mathrm{MnO}_{2}\right)$ as cathode material in batteries [16-19] and supercapacitors [20-23], that exhibits high theoretical capacity and can be produced in a cheap and sustainable way [24-31]. However, $\mathrm{MnO}_{2}$ has a low electronic conductivity that is undesirable in electrochemical devices [32,33], associated with an irreversible reduction in its capacitance at high voltage or high temperature and over several charge-discharge cycles [3437]. In this regard, considerable research efforts have been devoted to improve the electrochemical performance of $\mathrm{MnO}_{2}$-based electrodes by combining $\mathrm{MnO}_{2}$ with highly conductive materials such as metallic nanostructures, carbon nanotubes, graphene or conductive polymers (by polypyrrole, polyaniline, and polythiophene) [38-43]. In a rechargeable battery, the energy storage results from charging the electrical double layer at the electrode and from faradic reactions at the electrolyte interface. To improve the accessibility of electrolytic doping ions to the electrode surface, large-area electro-active electrodes must be constructed, hence the use of conductive polymers to provide a stable conductive environment for the $\mathrm{MnO}_{2}$ [44-53]. Among them, the conductive properties of polypyrrole (PPy), as well as its low cost, high theoretical specific capacity and good mechanical stability [38,54-57], have been used for the development of high-performance electrodes in supercapacitors, where $\mathrm{MnO}_{2}$ has been fixed by hydrothermal process [58], by chemical oxidative polymerization in-situ $[38,40]$, or used in the form of nanowires as a matrix [59]. 
In this work, we choose to insert $\mathrm{MnO}_{2}$ into PPy films grown by electrochemical polymerization on ITO substrate. We report herein the assessment of two different methods to insert the particles into the polymer matrix. The first method consisted of forming $\mathrm{MnO}_{2}$ in situ within the PPy/ITO electrode, while the second method involved first a preliminary adsorption of $\mathrm{Mn}^{2+}$ ions in the polymer, followed by a subsequent electrochemical reduction step at the electrode. The structural morphology of the resulting composite materials $\mathrm{MnO}_{2} / \mathrm{PPy} / \mathrm{ITO}$ was carried out by XRD and SEM studies. We performed cyclic voltammetry (CV), LSV (Linear sweep voltammetry) curves and electrochemical impedance spectroscopy (EIS) studies to evaluate oxygen reduction due to the great importance of active cathodes in rechargeable batteries.

\section{Experimental}

\subsection{Chemicals}

The monomer pyrrole (99\%), $\mathrm{MnCl}_{2}, \mathrm{KCl}, \mathrm{LiCLO}_{4}$ and acetonitrile were purchased from Sigma-Aldrich.

\subsection{Synthesis of PPy and composite film preparation}

Electropolymerization of pyrrole monomer was performed onto ITO substrates in a three-electrode cell, with a Pt wire as counter electrode, a saturated calomel electrode (SCE) as the reference electrode and ITO sample $\left(1 \times 2 \mathrm{~cm}^{2}\right)$ as working electrode, previously cleaned successively with $\mathrm{HNO}_{3}$, acetone, ethanol and distilled water. The electropolymerization was carried out by cyclic voltammetry over 20 cycles between -1.0 to $1.2 \mathrm{~V} v \mathrm{~s}$. SCE at $20 \mathrm{mV} . \mathrm{s}^{-1}$, in acetonitrile containing $0.1 \mathrm{M}$ of $\mathrm{LiClO}_{4}$ and $0.1 \mathrm{M}$ of Pyrrole [60]. The resulting electrode (estimated area of $1 \mathrm{~cm}^{2}$ ), named as PPy/ITO, was thoroughly rinsed with water solution to 
remove any remaining monomeric traces. Two different methods have been used to incorporate $\mathrm{MnO}_{2}$ particles into PPy film.

First method: $\mathrm{MnO}_{2}$ was electrodeposited directly on a PPy / ITO electrode by performing 10 cycles between 0.4 and $1.5 \mathrm{~V}$ (vs SCE) in an aqueous solution of $0.4 \mathrm{M} \mathrm{KCl}$ and $0.05 \mathrm{M} \mathrm{MnCl}_{2}$., which we called the "direct method" $\left(\mathrm{d}-\mathrm{MnO}_{2}\right)$.

Second method: $\mathrm{MnCl}_{2}$ was first adsorbed after simple immersion of a PPy / ITO electrode in an aqueous solution containing $10^{-2} \mathrm{M} \mathrm{KCl}$ and $0.05 \mathrm{M} \mathrm{MnCl}_{2}$ for different immersion times (5 and 10 minutes) allowing by electrostatic interactions the exchange of manganese ions with the counterions initially present in the PPy film. A subsequent step of electrochemical reduction resulted in the formation of $\mathrm{MnO}_{2}$ in the PPy/ITO electrode by cyclic voltammetry ( 10 cycles) in the potential range of $0.2-1.5 \mathrm{~V}$ vs SCE in $0.1 \mathrm{M} \mathrm{KCl}$. The second method was called "indirect method" (i- $\left.\mathrm{MnO}_{2}\right)$.

The resulting composite electrodes were called $\mathrm{MnO}_{2} / \mathrm{PPy} / \mathrm{ITO}$.

\subsection{Electrode characterization}

The XRD were examined by X'Pert Pro MPD X-ray diffractometer using $\mathrm{Cu}-\mathrm{K} \alpha$ radiation $(\lambda=0.154059 \mathrm{~nm})$. The FTIR were traced by Nicolet 6700 . The electrochemical behavior of the $\mathrm{MnO}_{2} / \mathrm{PPy} / \mathrm{ITO}$ electrodes with respect to $\mathrm{O}_{2}$ reduction was evaluated by linear sweep voltammetry (LSV). LSV was conducted from OCP value of $1.4 \mathrm{~V}$ to $0 \mathrm{~V}$ vs. SCE at a scan rate of $25 \mathrm{mV} . \mathrm{s}^{-1}$ in $0.1 \mathrm{M} \mathrm{KCl}$. Electrochemical impedance spectroscopy (EIS) was conducted using Metrohm Autolab (PGSTAT302N) by scanning the frequencies between 100 $\mathrm{kHz}$ to $0.1 \mathrm{~Hz}(10 \mathrm{mV}$ amplitude $)$, at $E_{\text {appl }}=0.2 \mathrm{~V}$ vs. SCE. 


\section{Results and discussion}

\subsection{Characterization of the composite film $\mathrm{MnO}_{2} / \mathrm{PPy} / \mathrm{ITO}$}

The growth of PPy on ITO is shown on the typical cyclic voltammograms in Fig. 1, characterized by a pair of redox peaks located at $0.5 \mathrm{~V}$ vs. SCE and attributed to the electrochemical transition from the reduced form of PPy to the oxidized state [28-29]. Inset in Fig. 1 shows the formation of a three-dimensional polymer network observed by SEM characterization.

Fig. 1 Cyclic voltammetry of Pyrrole $(0.1 \mathrm{M})$ at the electrode ITO performed over 20 cycles between -1 and $1.2 \mathrm{~V}$ vs. SCE at scanning rate $20 \mathrm{mV} \cdot \mathrm{s}^{-1}$, in the electrolyte $0.1 \mathrm{M}$ $\mathrm{LiClO}_{4}$ in acetonitrile. Insert: SEM image of PPy/ITO sample.

The $\mathrm{MnO}_{2} / \mathrm{PPy} / \mathrm{ITO}$ composite films were synthesized by entrapping the metal salt to give metal particles in a subsequent reduction step, using two methods. In the direct method (d$\mathrm{MnO}_{2}$ ), $\mathrm{MnO}_{2}$ was formed in situ on the PPy/ITO electrode from an aqueous solution containing $\mathrm{MnCl}_{2}$ after ion-exchange subjected to ten successive scans in the potential range starting from the open potential of 0.4 to $1.5 \mathrm{~V} v s$. SCE in $\mathrm{KCl}$ (Fig. 2a). The CV profile (Fig. 2b) shows the oxidation peak of $\mathrm{Mn}(+\mathrm{II})$ in $\mathrm{Mn}(+\mathrm{IV})$ located at $1.25 \mathrm{~V}$ vs. SCE and the reduction peak of $\mathrm{Mn}(+\mathrm{IV})$ in $\mathrm{Mn}(+\mathrm{II})$ at $0.65 \mathrm{~V}$ vs. SCE, according to the one-step process related to the reaction (1) [61-63].

$\mathrm{Mn}^{2+}+2 \mathrm{H}_{2} \mathrm{O} \leftrightarrows \mathrm{MnO}_{2}+4 \mathrm{H}^{+}+2 e^{-}$ 
Fig. 2.(a,b) Cyclic voltammograms of PPy/ITO electrode over 10 scans in the potential range 0.4 - $1.5 \mathrm{~V}$ vs. SCE in aqueous solution containing $0.4 \mathrm{M} \mathrm{KCl}$ and $0.05 \mathrm{M} \mathrm{MnCl}$. (c,d) Cyclic voltammograms of ITO/PPy electrode for 10 scans in the potential range 0.2

\section{- $1.5 \mathrm{~V}$ vs. SCE in $0.4 \mathrm{M} \mathrm{KCl}$ solution, after immersion of the electrode in $10^{-2} \mathrm{M} \mathrm{MnCl}_{2}$ and $0.4 \mathrm{M} \mathrm{KCl}$ solution. Potential scan rate is $20 \mathrm{~m} \mathrm{V.s} \mathrm{s}^{-1}$.}

In the indirect method $\left(\mathrm{i}-\mathrm{MnO}_{2}\right), \mathrm{MnO}_{2}$ was formed within the PPy/ITO electrode in two successive steps: (i) adsorption of $\mathrm{Mn}^{2+}$ ions in the polymer according to two different times of soaking: 5 and 10 minutes, and (ii) formation of metal particles in a subsequent step of electrochemical reduction at the electrode in $\mathrm{KCl}$ solution. The resulting cyclic voltammetry, in Fig. 2c, shows an intense peak at $0.9 \mathrm{~V}$ corresponding to the oxidation of the incorporated $\mathrm{Mn}(\mathrm{II})$ in $\mathrm{Mn}(\mathrm{IV})$ on the surface of the PPy/ITO electrode. The lower value of oxidation potential for the second method reflects the easier transformation of $\mathrm{Mn}^{2+}$ ions to $\mathrm{MnO}_{2}$, which are more readily available in the matrix after the absorption step. Furthermore, according to the current density values on the first cyclic voltammetry curves in Figure 2d, a soak time of 5 min for the electrode in the $\mathrm{MnCl}_{2}$ solution allows the incorporation of increased $\mathrm{MnO}_{2}$ into the polymer. It can therefore be proposed that $\mathrm{MnO}_{2}$ acts as electron transfer mediators in the nucleation, formation and growth of the PPy film on the ITO surface.

The morphology of the as-fabricated materials, obtained by cyclic voltammetry, was analyzed by SEM. The nucleation and growth of PPy occurs randomly, forming irregularly shaped particles with defined boundaries, which are typical morphologies of polypyrroles. This morphology depends on the polymerization charge and the nature of the counter anions. Contrary to PPy films characterized by an irregular morphology with remaining particle sizes as nucleation sites varying from 0.10 to $5.0 \mu \mathrm{m}$ (inset SEM images in Fig.1), the composites electrodes present different morphologies (Fig. 3). For the d-MnO 2 method, the surface morphology of $\mathrm{MnO}_{2} / \mathrm{PPy} / \mathrm{ITO}$ is characterized (Fig. 3a) by a homogeneous cauliflower-like 
structure. For the $\mathrm{i}-\mathrm{MnO}_{2}$ method, the surface morphology of $\mathrm{MnO}_{2} / \mathrm{PPy} / \mathrm{ITO}$ (Fig. 3a and b) is rather characterized by a smooth and dense layer surrounded by grains. According to the soaking time, the PPy/ITO electrode in $\mathrm{Mn}^{2+}$ solution, the grains seem to be localized on the surface of the film for the soaking time of 5 minutes, and rather embedded within the film for the longer soaking time of 10 minutes.

\section{Fig.3 SEM images and EDS of (a,a') d-MnO2/PPy/ITO, (b,b') i-MnO $2 / \mathrm{MPy}_{2} / \mathrm{ITO}(5 \mathrm{~min})$ and (c,c') i-MnO2/PPy/ITO (10 min).}

EDX spectra of the representative electrodes (Fig. 3a',b',c'), qualitatively shows the successful existence of $\mathrm{MnO}_{2}$ in the PPy matrix with the presence of intense rays at 5.9 and $6.5 \mathrm{keV}$. The amount of $\mathrm{MnO}_{2}$ varies with the method of synthesis: with the d- $\mathrm{MnO}_{2}$ method, it seems that a higher amount is obtained due to the relatively good conductivity of PPy film. In addition, EDX spectra show the presence of carbon, nitrogen, characteristic of the polymer PPy, and the presence of chlorine and oxygen comes from the doping of PPy with perchlorate ions. The presence of $\mathrm{Si}, \mathrm{In}, \mathrm{O}$ and $\mathrm{Sn}$ atoms are characteristic of the ITO substrate.

The presence of $\mathrm{MnO}_{2}$ in the composite electrodes was also confirmed by XRD analyses. Figure 4 presents the pattern of pure PPy, with a broad peak centered at $2 \theta=25^{\circ}$ assigned to the repeating unit of the pyrrole ring and revealing the amorphous nature of the resulting polymer. This observation is in agreement with PPy materials obtained by classical chemical or electrochemical methods $[64,65]$. Diffraction peaks indexed by an asterix correspond to the ITO substrate. The two broad peaks at $2 \theta$ values of $37.1^{\circ}$ and $42.2^{\circ}$ correspond to the (131) and (300) crystal planes, respectively, which confirm the crystallographic variety $\gamma-\mathrm{MnO}_{2}$ in agreement with the literature (JCPDS no. 14-0644) [66]. Due to the PPy amorphous nature, $\mathrm{MnO}_{2} / \mathrm{PPy} / \mathrm{ITO}$ samples have an X-ray profile similar to that of pure $\mathrm{MnO}_{2}$, indicating no noticeable change in crystal structure. 


\section{Fig. 4. a: XRD diffraction patterns of $\mathrm{MnO}_{2}$, PPy/ITO, PPy/MnO$/ / \mathrm{ITO}$ (i-MnO 2 and $\left.t_{\text {soaking }}=5 \mathrm{~min}\right), \mathrm{PPy} / \mathrm{MnO}_{2}\left(\mathrm{i}-\mathrm{MnO}_{2}\right.$ and $\left.\mathrm{t}_{\text {soaking }}=10 \mathrm{~min}\right)$, and $\mathrm{PPy} / \mathrm{MnO}_{2} / \mathrm{ITO}(\mathrm{d}-$ $\mathrm{MnO}_{2}$ ). b: FTIR spectra of PPy and PPy/MnO 2 films.}

The FTIR spectra of PPy and PPy/MnO 2 films are shown in Figure 4.b. The observed bands confirm the formation of polypyrrole. The absorption bands at 1550, 1450, and $1030 \mathrm{~cm}^{-1}$ are characteristic of the C-C, C-N, and C-H stretching vibrations on the PPy rings [67], whereas the bands observed at 1300 and $1160 \mathrm{~cm}^{-1}$ correspond to the in-plane deformation of the $\mathrm{C}-\mathrm{H}$ and the $\mathrm{C}-\mathrm{N}$ stretching vibrations [68]. The other bands around $1045 \mathrm{~cm}^{-1}$ reflect the N-H plane strain vibration of the doped PPy [69]. Although the $\mathrm{PPy} / \mathrm{MnO}_{2}$ and PPy spectra are very similar, we note that the position and the intensity of the characteristic bands of the polypyrrole in $\mathrm{PPy} / \mathrm{MnO}_{2}$ composites are influenced by the insertion of $\mathrm{MnO}_{2}$, as already observed in the literature [70,71].

\subsection{Electrochemical characterization of $\mathrm{MnO}_{2} / \mathrm{PPy} / \mathrm{ITO}$}

EIS experiments were conducted for further characterizing the $\mathrm{PPy} / \mathrm{MnO}_{2} / \mathrm{ITO}$ electrodes. Fig. 5 shows the Nyquist plots with are characterized by a typical semicircle in the high frequency region for all samples, which corresponds to the charge transfer resistance $\left(\mathrm{R}_{c t}\right)$ of the electrodes. For all samples, the semicircle starts at the same value, indicating that the resistance of the electrolyte remains unchanged.

Fig.5. Complex-plane Nyquist impedance plots at $\mathbf{E}_{\text {appl }}=0.2$ V vs. SCE 
in 0.1 M KCl, for the electrodes ITO, PPy/ITO, PPy/MnO $/$ ITO(i-MnO $\mathrm{M}_{2}$ and $\mathrm{t}_{\text {soaking }}=5$ $\min ), \mathrm{PPy}_{/ \mathrm{MnO}_{2}\left(\mathrm{i}-\mathrm{MnO}_{2} \text { and } \mathrm{t}_{\text {soaking }}=10 \mathrm{~min}\right) \text {, and PPy/MnO}} / \mathrm{ITO}\left(\mathrm{d}-\mathrm{MnO}_{2}\right)$.

For a given electrode, the lower $R_{\mathrm{ct}}$ is, the higher is the electrical conductivity. The results gathered in Table 1 show that $R_{\mathrm{ct}}=175,75,13$ and $8 \Omega \mathrm{cm}^{2}$ for PPy, PPy/d-MnO $2, \mathrm{PPy} / \mathrm{i}-\mathrm{MnO}_{2}$ (5 min) and ITO/PPy i- $\mathrm{MnO}_{2}(10 \mathrm{~min})$, respectively. In the presence of $\mathrm{MnO}_{2}$, the $R_{\mathrm{ct}}$ values decrease drastically, inducing a lower interfacial charge transfer resistance [72] and thus higher electrical conductivity of the electrodes compared to PPy. $\mathrm{R}_{\mathrm{ct}}$ is even lower when $\mathrm{MnO}_{2}$ was incorporated in the polymer by the indirect method compared to the direct method. The modelling of EIS data by a representative equivalent electrical circuit enables the determination of $Q_{\mathrm{CPE}}$ (constant phase element), from the equation $Q_{\mathrm{CPE}}=\left\{(\mathrm{Ci} \omega)^{\alpha}\right\}^{-1}$. The $\alpha$ values are between 0.66 and 0.83 for all composite electrodes, suggesting the uniformity and the homogeneity of the materials.

Table 1. Impedance parameters of the composite electrodes.

Given the great importance of the development of electrode materials for $\mathrm{O}_{2}$ reduction in batteries, the behavior of the composite electrodes has been studied by LSV from 1.4 to $0 \mathrm{~V}$ vs. SCE in $1 \mathrm{M} \mathrm{KCl}$. As shown in Fig.6, the oxygen reduction current starts without overpotential at $1.4 \mathrm{~V}$ vs. SCE, and the current densities show a semi-plateau, resulting from the control of the electrocatalytic reaction by diffusion of the oxygen to the electrode surface. The $\mathrm{MnO}_{2} / \mathrm{ITO}$ electrode delivers the lowest current density about $-0.9 \mathrm{~mA} . \mathrm{cm}^{-2}$, confirming the crucial role of PPy in improving electrode performance. 
Fig. 6. LSV of the composite electrodes ITO/PPy/MnO 2 in aqueous $1 \mathrm{M} \mathrm{KCl}$ electrolyte between 1.4 and $0 \mathrm{~V}$ vs. SCE at a scan rate of $25 \mathrm{mV} \mathrm{s}^{-1}$.

The maximal current density of $\mathrm{O}_{2}$ reduction for $\mathrm{d}-\mathrm{MnO}_{2} / \mathrm{PPy} / \mathrm{ITO}$, i$\mathrm{MnO}_{2} / \mathrm{PPy} / \mathrm{ITO}(10 \mathrm{~min})$ and $\mathrm{i}-\mathrm{MnO}_{2} / \mathrm{PPy} / \mathrm{ITO}(5 \mathrm{~min})$ electrode is $-4.9,-7.6$ and $-7.9 \mathrm{~mA} . \mathrm{cm}^{-2}$, respectively. These values reveal the importance of the synthesis technique used in the design of efficient $\mathrm{MnO}_{2} / \mathrm{PPy}$ composites. In the indirect method, we assume that the amount of $\mathrm{MnO}_{2}$ in PPy affords a close contact between the electrode material and the electrolyte. The maximal current density delivered by $\mathrm{i}-\mathrm{MnO}_{2} / \mathrm{PPy} / \mathrm{ITO}(5 \mathrm{~min})$ electrode is $-7.9 \mathrm{~mA} / \mathrm{cm}^{2}$, which is eight times the current density delivered by the electrode without PPy. This result shows the advantage of possible applications of $\mathrm{MnO}_{2}$ and PPy to prepare efficient electrodes. In comparison with literature, our composite polypyrrole/ $\mathrm{MnO}_{2}$ cathodes have a high and competitive efficiency for oxygen reduction reaction (ORR) with the reported $\mathrm{MnO}_{2}$ cathodes. As an example, efficient $\mathrm{MnO}_{2}$-based electrocatalysts have been synthesized for ORR, such as multi-walled $\mathrm{MnO}_{2} / \mathrm{PPy} / \mathrm{MnO}_{2}$ nanotubes [39], or $\alpha-\mathrm{MnO}_{2}$ nanowires prepared in the presence of an ionic liquid as structure-directing agent [73], able to generate current densities closed to $7 \mathrm{~mA} \cdot \mathrm{cm}^{-2}$. The introduction of nanoparticles into $\mathrm{MnO}_{2}$ materials has enable ORR to be boosted with delivered current densities close to $6 \mathrm{~mA} \cdot \mathrm{cm}^{-2}$, such as example with $\mathrm{Ag}$ in amorphous $\mathrm{MnO}_{2}$ mixed with carbon nanotubes [74], or with $\mathrm{Co}_{3} \mathrm{O}_{4}$ attached to the surface of $\mathrm{MnO}_{2}$ nanorods [75].

\section{Conclusion}

In this study, $\mathrm{MnO}_{2} / \mathrm{PPy}$ electrodes were successfully prepared and examined. The insertion of $\mathrm{MnO}_{2}$ in the polymer matrix was confirmed by DRX and EDX. SEM micrographs showed cauliflower-like growth on the deposited substrate. $\mathrm{MnO}_{2}$ grains of similar size were homogeneously distributed in the polymer. The composite electrode showed a decrease in 
charge transfer resistance and excellent electrochemical stability. Electrochemical experiments revealed that the composite materials prepared by the direct incorporation of $\mathrm{MnO}_{2}$ gave the highest performance for $\mathrm{O}_{2}$ reduction. This study contributes toward advances in the design of efficient $\mathrm{MnO}_{2} / \mathrm{PPy}$ composites suitable for rechargeable battery electrodes. 


\section{References}

1. S. Khamlich, Z. Abdullaeva, J. V. Kennedy, and M. Maaza, Appl. Surf. Sci. 405, 329 (2017).

2. P. P. Murmu, S. V. Chong, J. Storey, S. Rubanov, and J. Kennedy, Mater. Today Energy 13, 249 (2019).

3. K. Kaviyarasu, C. Maria Magdalane, D. Jayakumar, Y. Samson, A. K. H. Bashir, M. Maaza, D. Letsholathebe, A. H. Mahmoud, and J. Kennedy, J. King Saud Univ. - Sci. 32, $1516(2020)$.

4. S. S. Rathnakumar, K. Noluthando, A. J. Kulandaiswamy, J. B. B. Rayappan, K. Kasinathan, J. Kennedy, and M. Maaza, Sensors Actuators B Chem. 293, 100 (2019).

5. J. P. Painuly, Renew. Energy 24, 73 (2001).

6. K. Bilen, O. Ozyurt, K. Bakırc1, S. Karsl1, S. Erdogan, M. Yılmaz, and O. Comaklı, Renew. Sustain. Energy Rev. 12, 1529 (2008).

7. B. Dunn, H. Kamath, and J.-M. Tarascon, Science 334, 928 (2011).

8. J. Chow, R. J. Kopp, and P. R. Portney, Science (80-. ). 302, 1528 LP (2003).

9. B.-O. Park, C. D. Lokhande, H.-S. Park, K.-D. Jung, and O.-S. Joo, J. Power Sources 134, 148 (2004).

10. H.-K. Kim, T.-Y. Seong, J.-H. Lim, W. Ii Cho, and Y. Soo Yoon, J. Power Sources 102, 167 (2001).

11. C.-C. Hu and K.-H. Chang, J. Power Sources 112, 401 (2002).

12. A. K. Noordeen, S. Sambasivam, S. Chinnasamy, J. Ramasamy, and T. Subramani, J. Inorg. Organomet. Polym. Mater. 28, 73 (2018).

13. M. Yeganeh Shad, M. Nouri, A. Salmasifar, H. Sameie, R. Salimi, H. Eivaz Mohammadloo, A. A. Sabbagh Alvani, M. Ashuri, and M. Tahriri, J. Inorg. Organomet. Polym. Mater. 23, 1226 (2013). 
14. M. M. Doeff, J. Cabana, and M. Shirpour, J. Inorg. Organomet. Polym. Mater. 24, 5 (2014).

15. S. E. H. Etaiw and M. S. Ibrahim, J. Inorg. Organomet. Polym. Mater. 23, 340 (2013).

16. M. Toupin, T. Brousse, and D. Bélanger, Chem. Mater. 16, 3184 (2004).

17. R. N. Reddy and R. G. Reddy, J. Power Sources 132, 315 (2004).

18. C.-C. Hu and T.-W. Tsou, J. Power Sources 115, 179 (2003).

19. R. N. Reddy and R. G. Reddy, J. Power Sources 124, 330 (2003).

20. J. Zhou, H. Zhao, X. Mu, J. Chen, P. Zhang, Y. Wang, Y. He, Z. Zhang, X. Pan, and E. Xie, Nanoscale 7, 14697 (2015).

21. R. Rostami and M. Faraji, J. Inorg. Organomet. Polym. Mater. (2020).

22. S. K. Kandasamy and K. Kandasamy, J. Inorg. Organomet. Polym. Mater. 28, 559 (2018).

23. J. Zhang, J. Chen, Q. Zhang, R. Wang, and S. Wu, J. Inorg. Organomet. Polym. Mater. 29, $1400(2019)$

24. F. Liao, X. Han, D. Cheng, Y. Zhang, X. Han, C. Xu, and H. Chen, Ceram. Int. 45, 1058 (2019).

25. Q. Wang, Y. Ma, X. Liang, D. Zhang, and M. Miao, Chem. Eng. J. 371, 145 (2019).

26. Y. Chai, Z. Li, J. Wang, Z. Mo, and S. Yang, J. Alloys Compd. 775, 1206 (2019).

27. W. Guo, C. Yu, S. Li, Z. Wang, J. Yu, H. Huang, and J. Qiu, Nano Energy 57, 459 (2019).

28. P. Zhao, M. Yao, H. Ren, N. Wang, and S. Komarneni, Appl. Surf. Sci. 463, 931 (2019).

29. M. S. Kolathodi, M. Palei, T. S. Natarajan, and G. Singh, Nanotechnology 31, 125401 (2020).

30. S. Hong, X. Huang, H. Liu, and Z. Gao, J. Inorg. Organomet. Polym. Mater. 29, 1587 (2019).

31. S. Wu, J. Zhang, C. Sun, and J. Chen, J. Inorg. Organomet. Polym. Mater. (2020).

32. P. Lv, Y. Y. Feng, Y. Li, and W. Feng, J. Power Sources 220, 160 (2012). 
33. S. Grover, S. Shekhar, R. K. Sharma, and G. Singh, Electrochim. Acta 116, 137 (2014).

34. J.-W. Wang, Y. Chen, and B.-Z. Chen, J. Electrochem. Soc. 162, A1654 (2015).

35. S. R. Sivakkumar, J. M. Ko, D. Y. Kim, B. C. Kim, and G. G. Wallace, Electrochim. Acta 52, 7377 (2007).

36. H. Xia, M. O. Lai, and L. Lu, JOM J. Miner. Met. Mater. Soc. 63, 54 (2011).

37. K.-T. Lee, C.-B. Tsai, W.-H. Ho, and N.-L. Wu, Electrochem. Commun. 12, 886 (2010).

38. S. A. El-Khodary, I. S. Yahia, H. Y. Zahran, and M. Ibrahim, Phys. B Condens. Matter 556, 66 (2019).

39. H. Yuan, L. Deng, J. Tang, S. Zhou, Y. Chen, and Y. Yuan, ChemElectroChem 2, 1152 (2015).

40. R. Mahore, D. Burghate, S. Kondawar, A. Mahajan, and D. Nandanwar, Adv. Mater. Lett. 9, 538 (2018).

41. G. Yu, L. Hu, M. Vosgueritchian, H. Wang, X. Xie, J. R. McDonough, X. Cui, Y. Cui, and Z. Bao, Nano Lett. 11, 2905 (2011).

42. J. Chen, Y. Wang, J. Cao, Y. Liu, J.-H. Ouyang, D. Jia, and Y. Zhou, Electrochim. Acta 182, 861 (2015).

43. J. Bo, X. Luo, H. Huang, L. Li, W. Lai, and X. Yu, J. Power Sources 407, 105 (2018).

44. A. Bahloul, B. Nessark, N. Chelali, H. Groult, A. Mauger, and C. M. Julien, Solid State Ionics 204-205, 53 (2011).

45. H. Zouaoui, D. Abdi, A. Bahloul, B. Nessark, E. Briot, H. Groult, A. Mauger, and C. M. Julien, Mater. Sci. Eng. B 1 (2016).

46. W. Ni, D. Wang, Z. Huang, J. Zhao, and G. Cui, Mater. Chem. Phys. 124, 1151 (2010).

47. M. Nakayama, Y. Kashiwa, and K. Suzuki, J. Electrochem. Soc. 156, D125 (2009).

48. Q. Lu and Y. Zhou, J. Power Sources 196, 4088 (2011).

49. E. C. Rios, A. V Rosario, R. M. Q. Mello, and L. Micaroni, J. Power Sources 163, 1137 
(2007).

50. S. Karastogianni and S. Girousi, Anal. Chem. Insights 2016, 1 (2016).

51. H. Khan, K. Malook, and M. Shah, J. Mater. Sci. Mater. Electron. 29, 9090 (2018).

52. M. Wang, Q. Yang, T. Zhang, B. Zhu, and G. Li, RSC Adv. 6, 19952 (2016).

53. N. Boudissa, F. Z. Satour, A. Zouaoui, H. Benamrani, and A. Zegadi, J. Inorg.

Organomet. Polym. Mater. 30, 2677 (2020).

54. R. P. Mahore, D. K. Burghate, S. B. Kondawar, A. P. Mahajan, and D. V. Nandanwar, Adv. Mater. Lett. 9, 538 (2018).

55. S. Shivakumara and N. Munichandraiah, J. Alloys Compd. 787, 1044 (2019).

56. A. Bahloul, B. Nessark, E. Briot, H. Groult, A. Mauger, K. Zaghib, and C. M. Julien, J. Power Sources 240, 267 (2013).

57. J. Ji, X. Zhang, Z. Huang, X. Yu, H. Huang, Y. Huang, and L. Li, J. Nanosci. Nanotechnol. 17, 4356 (2017).

58. P. Li, Y. Yang, E. Shi, Q. Shen, Y. Shang, S. Wu, J. Wei, K. Wang, H. Zhu, and Q. Yuan, ACS Appl. Mater. Interfaces 6, 5228 (2014).

59. J. Zhang, Y. Shi, Y. Ding, W. Zhang, and G. Yu, Nano Lett. 16, 7276 (2016).

60. J. H. Kaufman, J. Electrochem. Soc. 131, 2092 (1984).

61. R. Inoue and M. Nakayama, ECS Trans. 41, 83 (2012).

62. S. Nijjer, J. Thonstad, and G. M. Haarberg, Electrochim. Acta 46, 395 (2000).

63. J.-P. Petitpierre, C. Comninellis, and E. Plattner, Electrochim. Acta 35, 281 (1990).

64. X. Chen, L. Liu, Z. Yan, Z. Huang, Q. Zhou, G. Guo, and X. Wang, RSC Adv. 6, 2345 (2016)

65. J.-G. Wang, B. Wei, and F. Kang, Rsc Adv. 4, 199 (2014).

66. W. Si, Y. Wang, Y. Peng, X. Li, K. Li, and J. Li, Chem. Commun. 51, 14977 (2015).

67. L. Yuan, C. Wan, and L. Zhao, Int. J. Electrochem. Sci. 10, 9456 (2015). 
68. J. Jang and J. H. Oh, Adv. Funct. Mater. 15, 494 (2005).

69. Y. C. Jung, N. G. Sahoo, and J. W. Cho, Macromol. Rapid Commun. 27, 126 (2006).

70. C. Wang, W. Wan, J.-T. Chen, H.-H. Zhou, X.-X. Zhang, L.-X. Yuan, and Y.-H. Huang, J. Mater. Chem. A 1, 1716 (2013).

71. X. Liang, M. Zhang, M. R. Kaiser, X. Gao, K. Konstantinov, R. Tandiono, Z. Wang, H.K. Liu, S.-X. Dou, and J. Wang, Nano Energy 11, 587 (2015).

72. X. Fan, X. Wang, G. Li, A. Yu, and Z. Chen, J. Power Sources 326, 357 (2016).

73. Y. Gu, G. Yan, Y. Lian, P. Qi, Q. Mu, C. Zhang, Z. Deng, and Y. Peng, Energy Storage Mater. 23, 252 (2019).

74. H. Sun, Z. Hu, J. Yu, and Z. Du, J. Electrochem. Soc. 167, 080539 (2020).

75. C. Cui, G. Du, K. Zhang, T. An, B. Li, X. Liu, and Z. Liu, J. Alloys Compd. 814, 152239 (2020). 
Table 1. Impedance parameters of the composite electrodes.

\begin{tabular}{|c|c|c|c|}
\hline Sample & $\mathbf{Z}_{\mathbf{C P E}}\left(\mu \mathbf{F} / \mathbf{c m}^{2}\right)$ & $R_{c t}\left(k \Omega \mathrm{cm}^{2}\right)$ & $\alpha$ \\
\hline ITO & 137.9 & 222.6 & 0.83 \\
\hline ITO/PPy & 138.7 & 174.7 & 0.78 \\
\hline ITO/PPy/d- $\mathrm{MnO}_{2}$ & 153.4 & 75.0 & 0.66 \\
\hline ITO/PPy/i-MnO 2 (5 min) & 178.6 & 13.1 & 0.67 \\
\hline ITO/PPy i-MnO 2 (10 min) & 194.1 & 8.2 & 0.74 \\
\hline
\end{tabular}




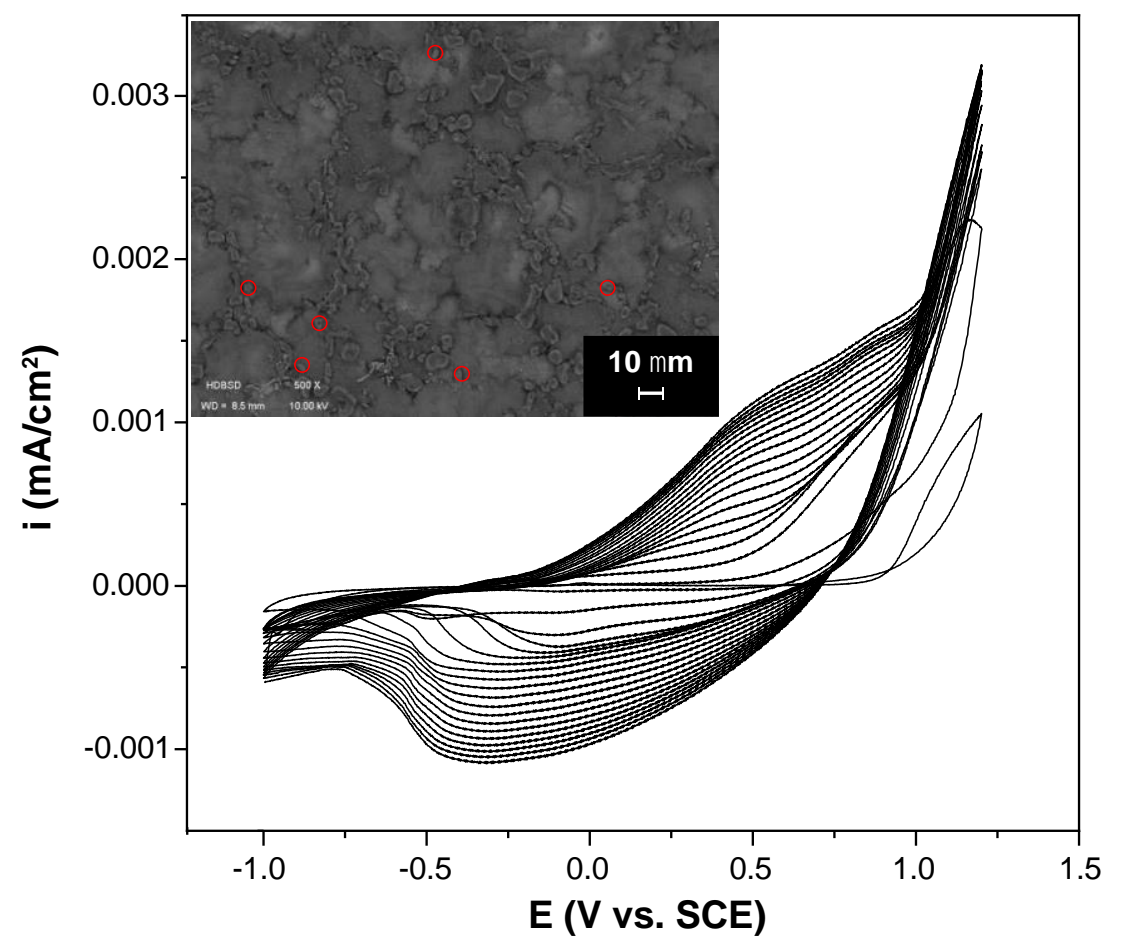

Fig. 1 Cyclic voltammetry of Pyrrole $(0.1 \mathrm{M})$ at the electrode ITO performed over 20 cycles between -1 and $1.2 \mathrm{~V}$ vs. SCE at scanning rate $20 \mathrm{mV}^{-1} \mathrm{~s}^{-1}$, in the electrolyte $0.1 \mathrm{M} \mathrm{LiClO}_{4}$ inacetonitrile. Insert: SEM image of PPy/ITO sample 

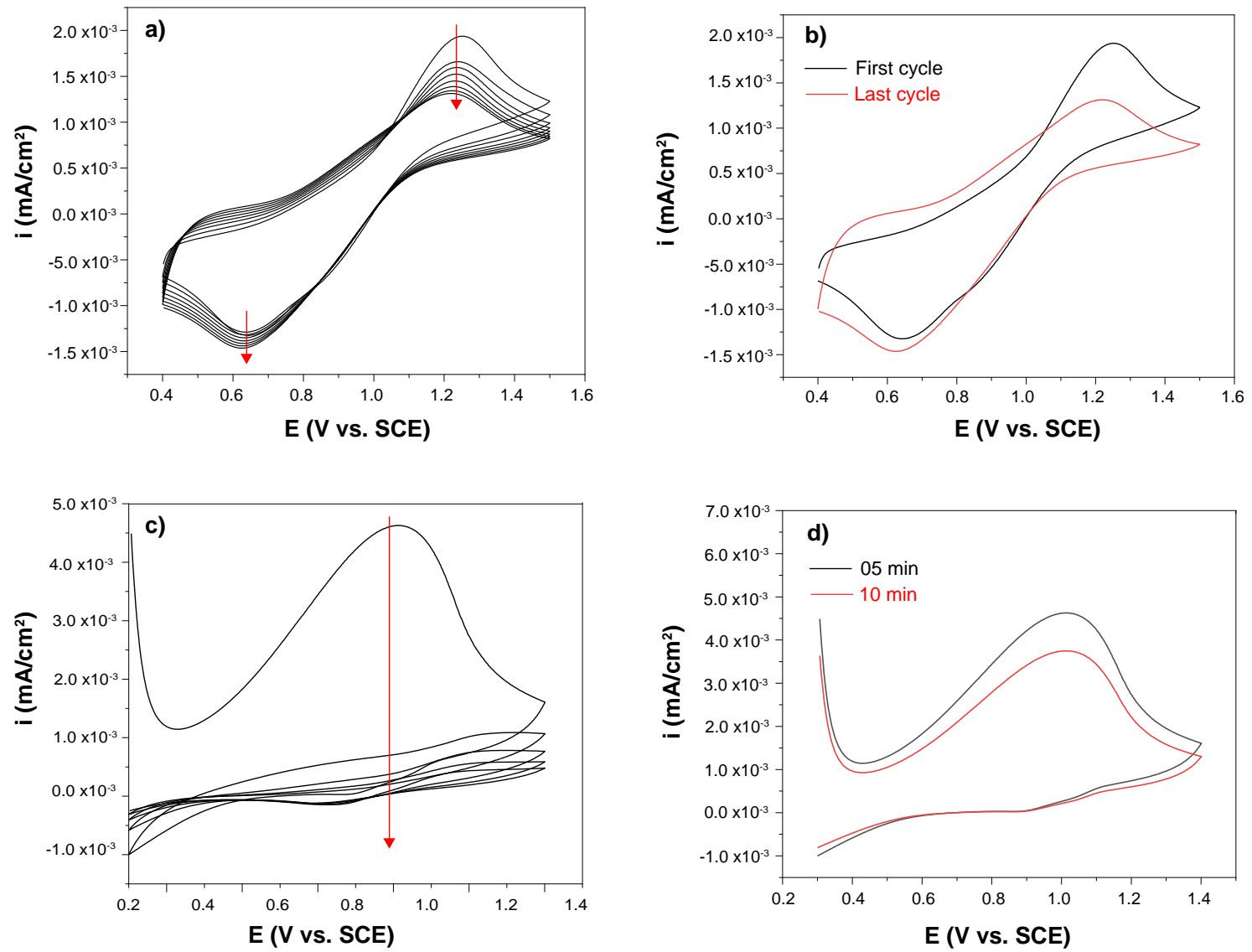

Fig. 2. (a,b) Cyclic voltammograms of PPy/ITO electrode over 10 scans in the potential range $0.4-1.5 \mathrm{~V} v s . \mathrm{SCE}$ in aqueous solution containing $0.4 \mathrm{M} \mathrm{KCl}$ and $0.05 \mathrm{M} \mathrm{MnCl}_{2}$. (c,d) Cyclic voltammograms of ITO/PPy electrode for 10 scans in the potential range $0.2-1.5 \mathrm{~V}$ vs. SCE in $0.4 \mathrm{M} \mathrm{KCl}$ solution, after immersion of the electrode in $10^{-2} \mathrm{M} \mathrm{MnCl}_{2}$ and $0.4 \mathrm{M} \mathrm{KCl}$ solution. Potential scan rate is $20 \mathrm{~m} \mathrm{V.s^{-1 }}$. 

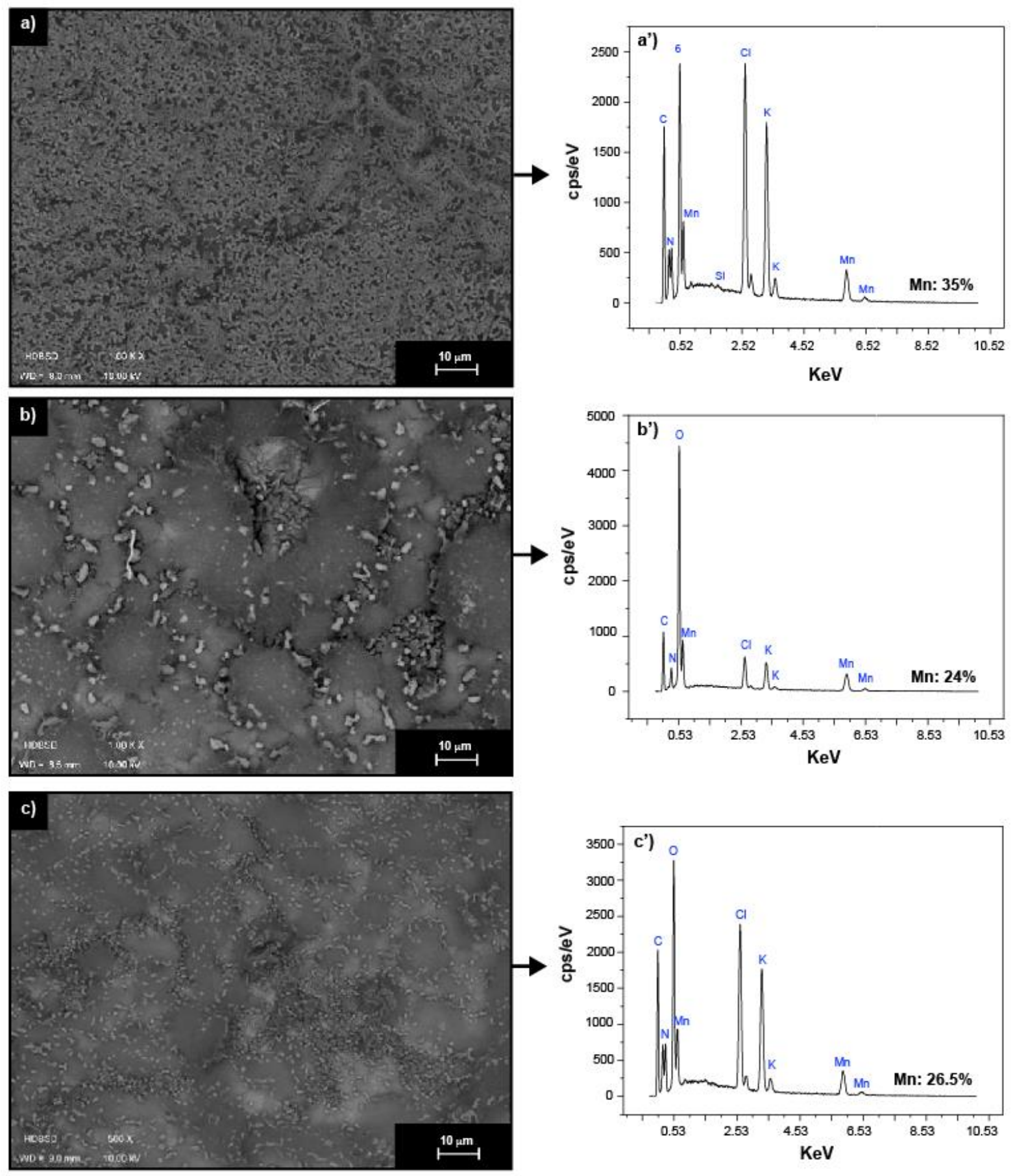

Fig.3 SEM images and EDS of (a,a') d-MnO $2 / \mathrm{PPy} / \mathrm{ITO},\left(\mathrm{b}, \mathrm{b}^{\prime}\right) \mathrm{i}-\mathrm{MnO}_{2} / \mathrm{PPy} / \mathrm{ITO}(5 \mathrm{~min})$ and (c,c') i-MnO $2 / \mathrm{PPy} / \mathrm{ITO}(10 \mathrm{~min})$. 

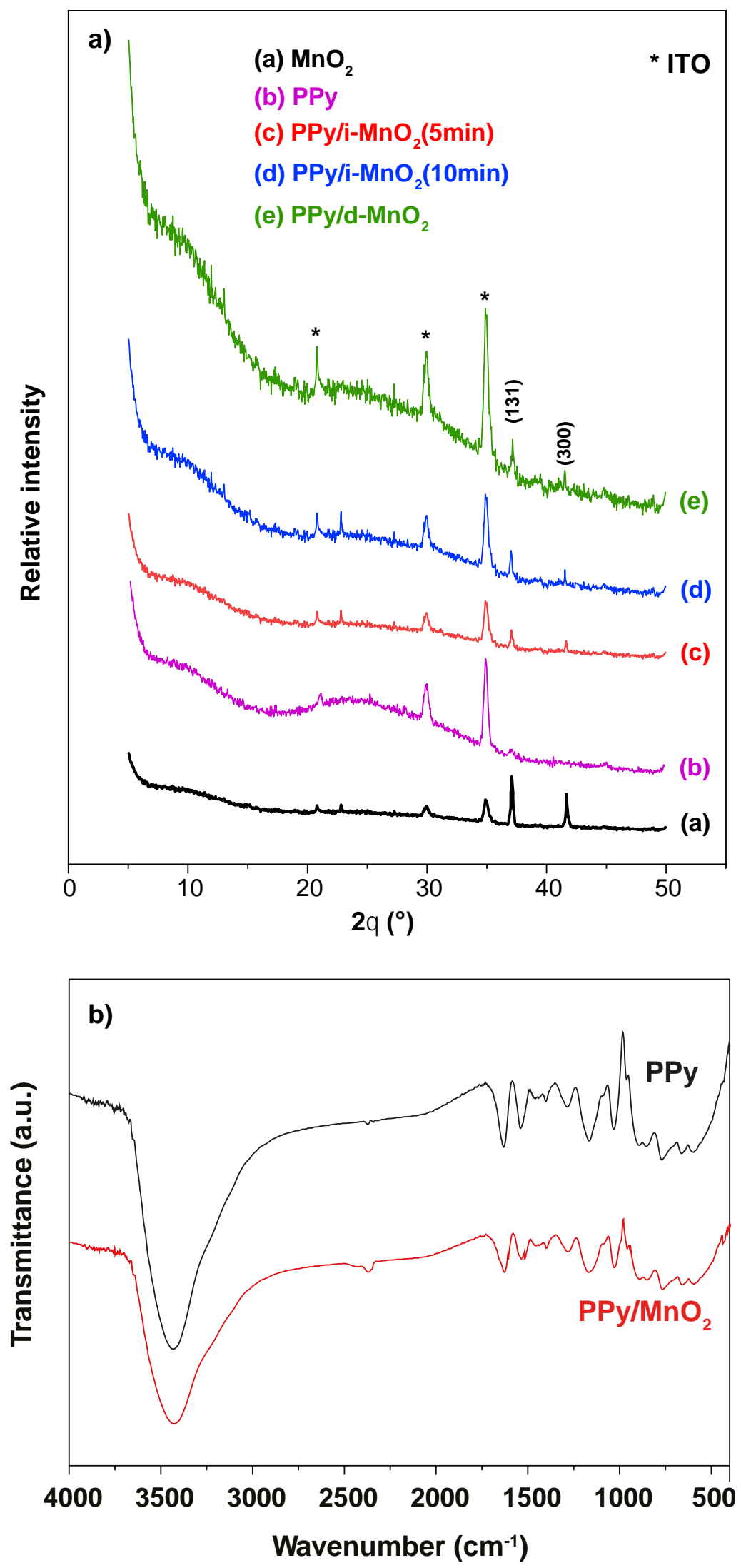

Fig. 4. a: XRD diffraction patterns of $\mathrm{MnO}_{2}$, PPy/ITO, PPy/MnO $/$ ITO $\left(\mathrm{i}-\mathrm{MnO}_{2}\right.$ and $\mathrm{t}_{\text {soaking }}=$ $5 \mathrm{~min}), \mathrm{PPy} / \mathrm{MnO}_{2}\left(\mathrm{i}-\mathrm{MnO}_{2}\right.$ and $\left.\mathrm{t}_{\text {soaking }}=10 \mathrm{~min}\right)$, and $\mathrm{PPy} / \mathrm{MnO}_{2} / \mathrm{ITO}\left(\mathrm{d}-\mathrm{MnO}_{2}\right) . \mathrm{b}:$ FTIR spectra of PPy and PPy/MnO 2 films. 


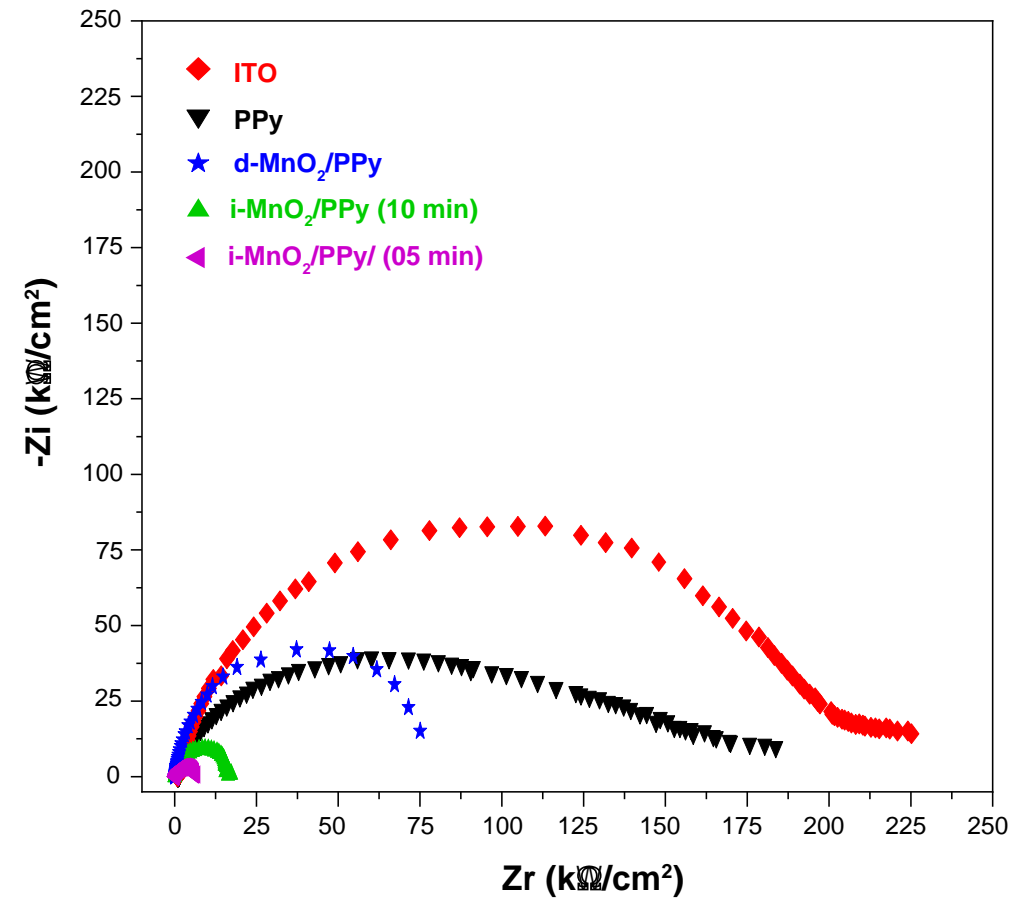

Fig.5. Complex-plane Nyquist impedance plots at $E_{\text {appl }}=0.2 \mathrm{~V}$ vs. SCE in $0.1 \mathrm{M} \mathrm{KCl}$, for the electrodes ITO, PPy/ITO, PPy/MnO $/ 2 \mathrm{ITO}\left(\mathrm{i}-\mathrm{MnO}_{2}\right.$ and $\left.\mathrm{t}_{\text {soaking }}=5 \mathrm{~min}\right)$, $\mathrm{PPy} / \mathrm{MnO}_{2}\left(\mathrm{i}-\mathrm{MnO}_{2}\right.$ and $\left.\mathrm{t}_{\text {soaking }}=10 \mathrm{~min}\right)$, and $\mathrm{PPy} / \mathrm{MnO}_{2} / \mathrm{ITO}\left(\mathrm{d}-\mathrm{MnO}_{2}\right)$. 


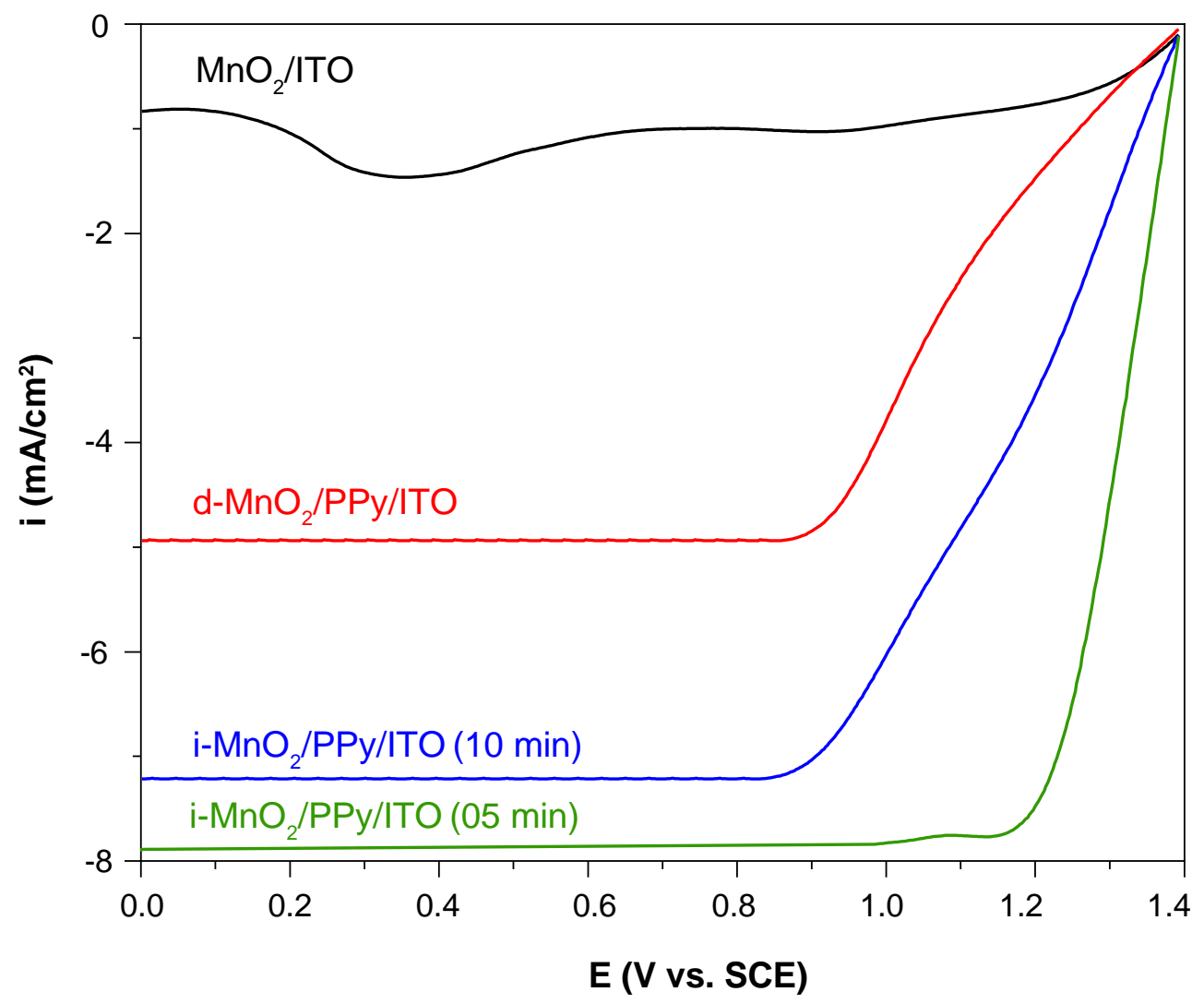

Fig. 6. LSV of the composite electrodes ITO/PPy/MnO 2 in aqueous $1 \mathrm{M} \mathrm{KCl}$ electrolyte between 1.4 and $0 \mathrm{~V}$ vs. SCE at a scan rate of $25 \mathrm{mV} . \mathrm{s}^{-1}$. 